\title{
Environmental color affects Nile tilapia reproduction
}

G.L. Volpato,

C.R.A. Duarte and A.C. Luchiari
Centro de Pesquisa em Bem-Estar Animal - RECAW, Laboratório de Fisiologia e Comportamento Animal, Departamento de Fisiologia, Instituto de Biociências, Universidade Estadual Paulista, Botucatu, SP, Brasil

\section{Correspondence \\ G.L. Volpato \\ Departamento de Fisiologia \\ Instituto de Biociências, UNESP \\ 18618-000 Botucatu, SP \\ Brasil \\ Fax: +55-14-6821-3744 \\ E-mail: volpato@ibb.unesp.br \\ Presented at the XVIII Annual Meeting of the Federação de Sociedades de Biologia Experimental, Curitiba, PR, Brazil, August 27-30, 2003. \\ Research as part of a fellowship from CNPq (No. 300644/1986-8) to G.L. Volpato.}

Publication supported by FAPESP.

Received April 25, 2003

Accepted January 5, 2004

\section{Abstract}

We investigated the effects of environmental color on the reproductive behavior of Nile tilapia, Oreochromis niloticus. Two environmental colors were tested by covering the aquarium $(60 \times 60 \times 40 \mathrm{~cm})$ with white (12 groups) or blue (13 groups) cellophane and observing reproductive behavior in groups of 2 males $(10.27 \pm 0.45 \mathrm{~cm})$ and 3 females $(10.78 \pm 0.45 \mathrm{~cm})$ each. After assignment to the respective environmental color (similar luminosity $=100$ to $120 \mathrm{Lux}$ ), the animals were observed until reproduction (identified by eggs in the female's mouth) or up to 10 days after the first nest building. Photoperiod was from 6:00 h to 18:00 h every day. Food was offered in excess once a day and water quality was similar among aquaria. Daily observations were made at 8:00, 11:00, 14:00 and 17:00 h regarding: a) latency to the first nest, b) number of nests, c) gravel weight removed (the male excavates the nest in the bottom of the aquarium), d) nest area, and e) mouthbrooding incubation (indication of reproduction). The proportion of reproducing fish was significantly higher (6 of 13) in the group exposed to the blue color compared the group exposed to the white color (1 of 12; Goodman's test of proportions). Moreover, males under blue light removed significantly larger masses of gravel (blue $=310.70 \pm 343.50 \mathrm{~g}>$ white $=130.38 \pm 102.70 \mathrm{~g} ; \mathrm{P}=$ 0.01 ) and constructed wider nests (blue $=207.93 \pm 207.80 \mathrm{~cm}^{2}>$ white $=97.68 \pm 70.64 \mathrm{~cm}^{2} ; \mathrm{P}=0.03$ ) than the control (white). The other parameters did not differ significantly between light conditions. We concluded that reproduction in the presence of blue light was more frequent and intense than in the presence of white light.

\section{Key words}

- Reproduction

- Environmental color

- Fish

- Nile tilapia

- Oreochromis niloticus

.................
The effect of environmental color on animal physiology and behavior is a developing field. Studies have concentrated on showing the effects of environmental colors on some mammals (1), birds (2) and fish (3), but the mechanisms are still unknown. In fish, some studies have shown that environmental color affects growth (4-6), feeding (7-9), food conversion rate (10), stress $(10,11)$, aggression
(12), and egg development (13).

The present study describes the effects of environmental color on reproduction by the Nile tilapia, Oreochromis niloticus (L.), a fish used in laboratory studies and also significant for world aquaculture. Reproduction is an activity closely related to fish fitness, which may be improved by some environmental colors (11). 
The study was conducted according to the ethical principles in animal research adopted by the Brazilian College of Animal Experimentation and was approved by the Bioscience Institute (UNESP) Ethics Committee for Animal Research (No. 121/02).

While the environment is composed of a wide range of colors and fish are presumably able to detect some of them (3), we specifically tested the effect of blue light on reproduction, using white light as control. Fanta (14) studied the effects of environmental colors on some behaviors of the Nile tilapia. Fanta visually analyzed some parameters, including male nest construction, and suggested that blue color improves male nest investment, but she did not investigate spawning. Considering other behaviors, she concluded that a green environment is the most beneficial for this species. However, Volpato and Barreto (11) tested the effect of light color on stress response in this species and showed that blue light prevents an increase in cortisol during stress. This effect and the known suppressive effect of stress on reproduction (15) support the notion that blue environmental color might improve reproduction in this species. Since white color is the usual illumination (fluorescent light) in laboratory studies, we used this color as control to analyze the effects of blue light on reproduction in Nile tilapia.

Adult Nile tilapia housed for about one year in an indoor 1200-liter tank (ca. 1 fish/ 6 liters; $\sim 6 \mathrm{~g} / \mathrm{l}$ ) were used as our stock population. During this housing period, temperature averaged $25 \pm 1^{\circ} \mathrm{C}$. Oxygen-saturated water and low levels of ammonia $(<0.5 \mathrm{ppm})$ and nitrite $(<0.05 \mathrm{ppm})$ were provided. Photoperiod was from 6:00 to 18:00 h every day. Food was offered in excess (>5\% of fish biomass) once a day.

The experimental design consisted of submitting groups of adult Nile tilapia (3 females and 2 males) to constant blue (experimental condition; 12 groups) or white (control condition; 13 groups) environments and observing reproductive behaviors (nest building and mouthbrooding) up to reproduction or up to 10 days after the first nest construction. Environmental color was imposed by covering each aquarium $(60 \times 60 \mathrm{x}$ $40 \mathrm{~cm}$; 100 liters) with white or blue cellophane and controlling light intensity to a narrow range from 100 to 120 Lux by adding cellophane layers. The bottom of the aquaria consisted of a 2-cm gravel layer to be used for nest building (a male activity in this species). Feeding, photoperiod and water quality were as in the holding condition. The experiment was carried out from June to November, 2002, and each replicate was run at the same time for the blue and white conditions.

Standard fish length and weight did not differ significantly between groups. Male length (mean $\pm \mathrm{SD}$ ) was $10.4 \pm 0.7 \mathrm{~cm}$ (blue) and $10.1 \pm 0.6 \mathrm{~cm}$ (white; $\mathrm{P}=0.20$, MannWhitney U-test), and body weight (mean \pm SD) was $37.9 \pm 5.7 \mathrm{~g}$ (blue) and $35.7 \pm 4.5 \mathrm{~g}$ (white; $\mathrm{P}=0.14$, Mann-Whitney U-test). Female length was $10.9 \pm 0.5 \mathrm{~cm}$ (blue) and $10.7 \pm 0.6 \mathrm{~cm}$ (white; $\mathrm{P}=0.09$, MannWhitney U-test), and body weight (mean \pm SD) was $41.7 \pm 5.3 \mathrm{~g}$ (blue) and $37.8 \pm 4.8 \mathrm{~g}$ (white; $\mathrm{P}=0.09$, Mann-Whitney U-test).

Observations were made daily at 8:00, 11:00, 14:00 and 17:00 h. Reproduction and associated behaviors were analyzed by quantification of gravel weight removed for nest building (see below), nest area, number of nests built divided by number of days after the first nest, latency (days) to initiate the first nest building, and reproduction frequency detected by the occurrence of mouthbrooding incubation. During reproduction, male Nile tilapia build nest and court females (16). Both sexes spawn into the nest and the female catches the eggs into her mouth for mouthbrooding (16). The eggs in the mouth of females are easily observed by visual inspection from outside the aquarium and are clear indicators of reproduction (16).

Another aspect quantified was nesting 
behavior. Each nest consisted of an excavation in the bottom shaped as an inverted cone. Thus, gravel weight removed for each nest construction was based on cone volume and calculated as $\mathrm{P}=\left\{((\pi \mathrm{h}) / 3)\left(\mathrm{R}^{2}+\mathrm{r}^{2}+\right.\right.$ $\mathrm{Rr})\} \mathrm{K}$, where $\pi=$ nest gravel weight, $\mathrm{h}=$ gravel ground depth, $\mathrm{R}=$ length of the longer nest radius, $r=$ length of the smaller nest radius, and $\mathrm{K}=$ relationship between gravel weight and its volume, previously calculated and corresponding to 0.95 .

The proportions of groups showing mouthbrooding and of non-breeding groups were compared between light color conditions by Goodman's proportion test. Nesting profiles were compared between white and blue conditions by the Mann-Whitney median test. Critical $\mathrm{P}$ values were considered at $\alpha=0.05$.

A significantly higher proportion (6/13) of groups exposed to blue light showed mouthbrooding compared to the groups exposed to white light (1/12) (Figure 1; Goodman's proportion test, $\mathrm{P}<0.05)$. Nests were built by all groups, irrespective of the environmental color. Fish under blue light removed a significantly larger absolute mass of gravel for nest building ( $\mathrm{P}=0.01$, MannWhitney test) and constructed significantly wider nests ( $P=0.03$, Mann-Whitney test) considering the nest set as a whole (Table 1). The other parameters, however, were not affected by environmental color (Table 1).

These results show that environmental color modulates the reproduction of the Nile tilapia, Oreochromis niloticus, with higher reproduction rates under blue light conditions. Since a similar light intensity was used in all groups, the different responses detected here between white and blue lights cannot be attributed to light intensity. While nests were constructed by all groups studied, showing that all groups were able to engage in reproductive behavior, the frequency of mouthbrooding was significantly higher in fish exposed to blue light than to white light. Effects of environmental color on reproduc- tion have also been reported for the "matrinxã" fish Brycon cephalus, with a significantly larger number of females spawning when hormonally induced reproduction occurred in a green environment compared to a white environment (8 of 9 versus 4 of 9 , respectively) (12). These results suggest that the effects of color on fish reproduction are species dependent.

Another aspect concerns the role of genders. Reproduction is a two-way behavior for which males and females must be motivated. In the Nile tilapia, the dominant male constructs nest(s) and courts females, attracting one to breed at the nest site (16). This interaction may result in spawning and then female mouthbrooding (17), which depends on the female's motivation for reproduction (18). The observations of nest building in the present study, however, showed that male reproductive motivation was probably affected by blue light. While males constructed nests in the presence of both environmental colors, a larger gravel mass

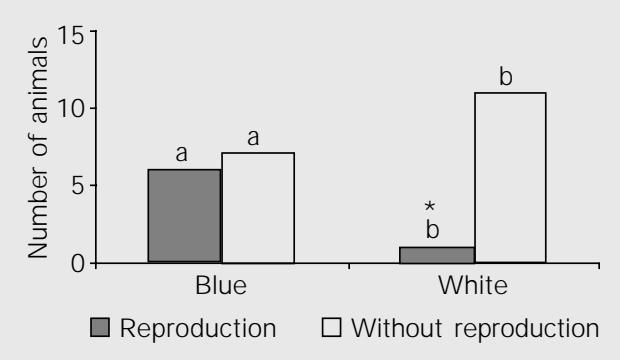

Figure 1. Reproductions observed in Nile tilapia groups under blue or white environmental colors. Different letters indicate significant differences between colors and the asterisk shows a statistically significant difference within the white color condition ( $P<0.05$, Goodman's test).

Table 1. Effects of environmental color on nest building in the Nile tilapia.

\begin{tabular}{lcc}
\hline Parameters of reproduction & \multicolumn{2}{c}{ Environmental color } \\
\cline { 2 - 3 } & White $(\mathrm{N}=12)$ & Blue $(\mathrm{N}=13)$ \\
\hline Gravel weight removed $(\mathrm{g})$ & $130.38 \pm 102.70$ & $310.70 \pm 343.50^{*}$ \\
Gravel weight removed $(\mathrm{g}) /$ male & $7.28 \pm 9.40$ & $4.10 \pm 2.72$ \\
$\quad$ & & \\
fish weight $(\mathrm{g})$ & $97.68 \pm 70.64$ & $207.93 \pm 207.80^{*}$ \\
Mean nest area $\left(\mathrm{cm}^{2}\right)$ & $0.44 \pm 0.53$ & $0.59 \pm 0.63$ \\
Number of nests/day & $6.92 \pm 4.73$ & $8.77 \pm 7.27$ \\
Latency to the first nest (days) & &
\end{tabular}

Data are reported as means $\pm \mathrm{SD}$. $\mathrm{N}=$ number of reproductive groups set up. $* \mathrm{P}<0.05$ compared to white light (Mann-Whitney U-test). 
was removed in the presence of blue light. Moreover, the mean area of the nests (considering the whole number of nests) was significantly larger in the blue light groups, in which reproduction frequency was also higher (Table 1). These results demonstrate that males were more motivated for reproduction by blue light. The gravel mass removed by males has been used as an indicator of reproductive investment in Nile tilapia (19).

In females, mouthbrooding indicates acceptance of male courtship. Since this occurred significantly in the blue environment, this color probably affected female motivation for reproduction. However, male motivation could also induce female reproductive behavior, and thus the explanation relies mainly on males, although this aspect requires further investigation.

Blue environmental color influenced fish reproductive behavior, although the mechanisms involved are not completely understood. The higher reproductive rate (Figure 1) and more intense nesting behavior in groups under blue light (Table 1) strongly suggest that this light stimulates reproduction in Nile tilapia. Since white light is the light background (fluorescent light) for laboratory studies all around the world, we used this as the control condition. Thus, under the conditions used (including the time limit of 10 days after building the first nest), reproduction was not expected and the higher frequency of reproduction in the blue light environment might represent improvement in reproduction. The other data about nest behavior also support this same conclusion since the nests were larger in groups under blue light (Table 1).

The mechanisms of the effect of color on reproduction are still unknown. However, stress may be involved because it is a process that suppresses reproduction $(15,20)$ and that is prevented by blue environmental color in Nile tilapia (11).

\section{Acknowledgments}

The authors thank P.E. Sobrinho for assistance with data collection; Dr. E.G. de Freitas, Dr. L.C. Jordão, MSc. R.E. Barreto, MSc. A.L. Marcondes and an anonymous referee for suggestions on this manuscript.

\section{References}

1. Birgersson B, Alm U \& Forkman B (2001). Colour vision in fallow deer: a behavioural study. Animal Behaviour, 61: 367-371.

2. Kovach J K (1993). Sources of behavioral deviation modeled by early color preferences in quail. III. Developmental stability and normative canalization. Behavior Genetics, 23: 369-377.

3. Levine J S \& MacNichol J r EJ (1982). Color vision in fishes. Scientific American, 216: 108-117.

4. Head $A D \&$ Malison J A (2000). Effects of lighting spectrum and disturbance level on the growth and stress responses of yellow perch Perca flavescens. J oumal of the World Aquaculture Society, 31: 73-80.

5. Tamazouzt L, Chatain B \& Fontaine $P$ (2000). Tank wall colour and light level affect growth and survival of Eurasian perch larvae (Perca fluviatilis L.). Aquaculture, 182: 85-90.

6. Dowing G \& Litvak MK (2000). The effect of photoperiod, tank colour and light intensity on growth of larval haddock. Aquaculture International, 7: 369-382.

7. Hinshaw M (1986). Factors affecting survival and growth of larval and early juvenile perch (Perca flavescens Mitchill). PhD thesis, North Carolina State University, Raleigh, NC, USA.
8. Duray MN, Estudillo CB \& Alpasan LG (1996). The effect of background color and rotifer density on rotifer intake, growth and survival of the grouper (Epinephelus suillus) larvae. Aquaculture, 146: 217-224.

9. Martin-Robichaud DJ \& Peterson RH (1998). Effects of light intensity, tank colour and photoperiod on swimmbladder inflation success in larval striped bass, Morone saxatilis (Walbaum). Aquaculture Research, 29: 539-547.

10. Papoutsoglou SE, Mylonakis G, Miliou H, Karakatsouli NP \& Chadio $S$ (2000). Effects of background color on growth performances and physiological responses of scaled carp (Cyprinus carpio L.) reared in a closed circulated system. Aquacultural Engineering, 22: 309-318.

11. Volpato GL \& Barreto RE (2001) Environmental blue light prevents stress in the fish Nile tilapia. Brazilian J oumal of Medical and Biological Research, 34: 1041-1045.

12. Volpato GL (2000). Aggression among farmed fish. In: Flos $R \&$ Creswell L (Editors), Aqua 2000: Responsible Aquaculture in the New Millenium. European Aquaculture Society Special Publication, No. 28, Nice, France.

13. Heichenback-Klinke HDH (1982). Enfermidades de los peces. 
Editora Acribia, Zaragoza, Spain.

14. Fanta $E$ (1995). Influence of background color on the behavior of the fish Oreochromis niloticus (Cichlidae). Arquivos de Biologia e Tecnologia, 38: 1237-1251.

15. Moberg GP \& Mench J A (2000). The Biology of Animal Stress: Basic Principles and Implications for Animal Welfare. CAB International, New York

16. Gonçalves-de-Freitas E \& Nishida SM (2000). Sneaking behaviour of the Nile tilapia. Boletim Técnico Cepta, 12: 1-5.

17. Tacon P, Ndiaye P, Cauty C, Le Menn F \& J alabert B (1996). Relationships between the expression of matemal behaviour and ovarian development in the mouthbrooding cichlid fish Oreochromis niloticus. Aquaculture, 146: 261-275.

18. Pitcher TJ (1986). The Behaviour of Teleost Fishes. Leaper \& Gard Ltd., Bristol, England.

19. Gonçalves-de-Freitas E (1998). Investimento reprodutivo e crescimento em machos de tilápia-do-Nilo. Doctoral thesis, Universidade Estadual Paulista (UNESP), São Paulo, SP, Brazil.

20. Barton BA (2002). Stress in fishes: A diversity of responses with particular reference to changes in circulating corticosteroids. Integrative and Comparative Biology, 42: 517-525. 